\title{
COMMUNICATION BARRIER BETWEEN NURSE AND PATIENT AT THE HOSPITAL: A SYSTEMATIC REVIEW
}

\author{
Andriyanto \\ Masters Program in Communication Sciences, Universitas Diponegoro
}

\begin{abstract}
Background: Communication is a multi-dimensional, multi-factorial phenomenon and a dynamic, complex process, closely related to the environment in hospital or related places. Nurses in hospital need to enhance their skill in communication to improve patient satisfaction. This study conducted a systematic review to describe the communication barrier between nurse and patient at the hospital.

Subjects and Method: This was a systematic review conducted by searching databases from EBSCO e-journals, Elsevier Science Direct, CINAHL Complete, and Google Scholar, published from 2012 to 2017. The literature was analyzed using critical appraisal tool.

Results: Communication barriers included job dissatisfaction due to workload, uncontrolled patient family presence, distrust of nurse competency, gender incompatibility, nurse lack of attention, delay and carelessness in providing information, lack of nurse responsibility, difference in language, over workload, patient family disorder, nurse reluctance to communicate, patient physical discomfort, physical and psychological complaint, language difficulty, limited nurse communication skill, insufficient time, busy environment, and noise. Communication barriers between nurse and patient affected the quality of health service.

Conclusion: Communication barriers between nurse and patient affect the quality of health service.
\end{abstract}

Keywords: communication barriers, nurses-patients, hospital

Correspondence:

Andriyanto. Masters Program in Communication Sciences, Universitas Diponegoro, Semarang, Central Java. Email: andrebae139@gmail.com. Mobile: 085229340032.

The $5^{\text {th }}$ International Conference on Public Health

Best Western Premier Hotel, Solo, Indonesia, February 13-14, 2019 | 175

https://doi.org/10.26911/theicph.2019.02.20 